This is the post print version of the article, which has been published in Nursing and health

\title{
CONNECTION BETWEEN ORGANIZATIONAL CULTURE AND CLIMATE AND EMPOWERMENT: THE PERSPECTIVE OF NURSE MANAGERS
}

Marija TRUS, RN, MNSc ${ }^{1,2}$

Nijole GALDIKIENE, RN, $\mathrm{PhD}^{3}$

Sigitas BALCIUNAS, $\mathrm{MSc}^{4}$

Philip GREEN, $\mathrm{PhD}^{5}$

Mika HELMINEN, MSc ${ }^{1,6}$

Tarja SUOMINEN, RN, $\mathrm{PhD}^{1}$

${ }^{1}$ Faculty of Social Sciences, Nursing Science, University of Tampere, Finland

${ }^{2}$ Department of Nursing, Faculty of Health Sciences, Klaipeda University, Lithuania

${ }^{3}$ Department of Nursing, Klaipeda State University of Applied Sciences, Lithuania

${ }^{4}$ Department of Public Administration, Social Research Center, Siauliai University, Lithuania

${ }^{5}$ University of Tennessee, Knoxville, USA

${ }^{6}$ Pirkanmaa Hospital District, Science Centre, Finland

Corresponding author: Marija Trus, Klaipeda University, Department of Nursing, Herkaus Manto st. 84, LT-92284, Klaipeda, Lithuania. E-mail: trus.marija.x@student.uta.fi

\section{RUNNING HEADING: CULTURE AND CLIMATE AND EMPOWERMENT}

\section{ACKNOWLEDGEMENTS}

The authors are grateful to professor Arvydas Martinkenas for his advice in statistical analysis, and to the nurse managers who participated in the research.

\section{FUNDING DETAILS}

The authors would like to thank the University of Tampere (Finland) and the Competitive State Research Financing of the Expert Responsibility Area of Tampere University Hospital (Grant 9S065) for their financial support of this study.

\section{DISCLOSURE}

The authors declare no conflict of interest. 


\begin{abstract}
Health care organizations differ from other institutions due to their unique structure and management. Organizational culture and climate are the key constructs that compose the organizational social context, and may have an impact on employees, like nurse managers, and the organization itself. This study aimed to analyze the connections between organizational culture and climate and work-related empowerment, and also to present culture and climate profiles at team and organization levels. The research was carried out in Lithuania among 193 nurse managers in 7 hospitals, using a questionnaire that measured organizational culture and climate (Organizational Social Context instrument), and work-related empowerment (Conditions for Work Effectiveness Questionnaire-II and Work Empowerment Questionnaire). The findings showed that nurse managers were both structurally and psychologically empowered when the organizational culture was proficient and resistant, and the climate was engaged and functional. These results suggest that nurse managers are more likely to be empowered when there is an appropriate organizational culture and climate in the workplace. Creating an empowering work environment may have a positive impact on individual and organizational outcomes.
\end{abstract}

Key words: empowerment, nurse manager, organizational climate, organizational culture, Organizational Social Context. 


\section{INTRODUCTION}

In the face of on-going health care reform processes, many organizations struggle to provide quality care, and experience a decrease in budget spending. Thus, the role of a nurse manager has changed from working in a clinical area, to focusing on managerial issues. Fulfilling a nurse manager's role requires the manager to create a healthy work environment that promotes the achievement of organizational goals, and implements change in nursing units (Baxter \& Warshawsky, 2014; Miltner et al., 2015; Gunawan \& Aungsuroch, 2017).

Organizational features such as its culture and climate are essential for the organization to reach success and perform properly. They are associated with service quality, staff turnover, positive outcomes and organizational effectiveness (Clark et al., 2012; Glisson, 2015). Moreover, there has been growing interest in the research on the culture and climate of health care organizations during the last decade (Aarons et al., 2012). Organizational culture builds on an organization's body and gives a complex understanding of organizational factors such as empowerment (Sinha, Priyadarshi, \& Kumar, 2016; Pradhan, Panda, \& Jena, 2017). Furthermore, when organizational work environments are perceived as a set of physicalsocial-psychological features of the organizational climate, this can result in a greater level of empowerment (Fan et al., 2016).

However, there has been a lack of research into the linkage of organizational aspects (culture and climate) and empowerment (structural and psychological). Therefore, it is important to pay attention to the nurse managers’ perceptions of this issue.

\section{LITERATURE REVIEW}

\section{Empowerment}

Empowerment can be understood from both structural and psychological approaches. Based on Kanter's (1993) theory, structural empowerment is seen as a nurse's ability to mobilize resources. When working in an empowered environment, nurses have access to several structures, in particular, information, support, resources and an opportunity to grow, and work with the sources of power. Alternatively, psychological empowerment is understood as being motivational, and grants people the ability to act and experience the feelings of selfconfidence (Van Bogaert et al., 2015; Spencer \& McLaren, 2016).

Creating an appropriate work environment which supports structural and psychological empowerment may lead to positive behaviors and attitudes (Spencer \& McLaren, 2016). Furthermore, structural and/or psychological empowerment can be linked with an individual's behavior and attitudes such as burnout, organizational commitment, work 
satisfaction, intent to stay in the present work, and engagement (Van Bogaert et al., 2015; Meng et al., 2015; 2016).

\section{Organizational culture and climate}

Culture and climate represent a social context composed of interpersonal networks which constrain and promote certain behaviors and interactions in the organization where individuals work. Different types of behavior (e.g. the implementation of innovations, commitment, task engagement) are influenced by the organizational social context (Aarons et al., 2012; Schneider \& Barbera, 2014; Glisson \& Williams, 2015).

Culture and climate are multidimensional and related concepts. Organizational culture includes the behavioral norms and expectations that guide the way workers do their work in a particular work environment, while organizational climate refers to the perception of the psychological impact that the work environment has on a worker's individual well-being and functioning (Aarons et al., 2012; Glisson, Green, \& Williams, 2012; Glisson \& Williams, 2015).

Organizational culture is an organizational-level construct and represents behavioral expectations and values (Glisson, Green, \& Williams, 2012; Glisson et al., 2014; Glisson, 2015). Meanwhile, organizational climate is an aggregate construct and can be understood with reference to a psychological climate described as "individual employee perceptions regarding the impact of the work environment on their personal well-being” (Williams \& Glisson, 2014, p. 758).

\section{Connection between culture and climate and empowerment}

There is some evidence that organizational culture and climate and empowerment are connected. According to Fan et al. (2016), structural empowerment promotes managers to undertake special actions for creating an appropriate work environment by providing workers with access to the following empowering structures (proposed by Kanter, 1993): access to information, support, resources, opportunities to grow, and formal and informal power. Moreover, Pradhan, Panda, and Jena (2017) considered that the psychological empowerment in an organization can be improved with the presence of an appropriate organizational culture in the workplace. However, any information as to how organizational culture and climate are connected to work-related empowerment from the perspective of nurse managers is limited.

\section{PURPOSE}


This study was conducted to find out what kind of connection may exist between organizational culture and climate, and the work-related empowerment of nurse managers. The investigation was undertaken both at team and organization levels, which helped to highlight differences between and within teams and organizations, and to present culture and climate profiles.

\section{METHODS}

\section{Setting and sampling}

Quantitative research with a correlational design was conducted. The participants of the presented study were nurse managers working among seven university and general level hospitals in Lithuania. The number of beds in each hospital varied from 700 to 1500 . The hospitals were similar in the health care services they provided and their organizational structure.

The sample size was calculated with a Sample Power 3 with 5\% standard error and $95 \%$ confidence level, and a minimum power of $80 \%$. The sample size achieved for the research met these requirements.

A primary meeting for all nurse managers in each hospital was organized to present the study. The data was collected in 2012 over a period of four months and included all of the nurse managers who were present during the research period. The overall response rate was $97 \%$.

In total, 193 nurse managers were involved in the research, all of whom were women. In accordance with the requirements of the instrument used (Glisson \& James, 2002), the nurse managers were categorized into teams. The number of respondents in each team ranged from 5 to 14 . Altogether, 22 teams participated in the research. The teams were formed based on individuals working in the same main clinical area, having common tasks and a common supervisor (chief nurse). The data collection was performed during arranged meetings for each team, in particular 7 medical, 6 surgical, 3 infectious diseases, 3 psychiatric, 2 midwifery, 1 elderly care. The researcher was present in the room during the data collection, but the questionnaires were completed individually by nurse managers and returned in sealed envelopes.

\section{Instruments}

The questionnaire consisted of three parts: socio-demographic characteristics, items measuring work-related empowerment, and items measuring organizational culture and climate. The items concerning work-related empowerment comprised of structural and 
psychological empowerment elements. Structural empowerment was measured by the Conditions for Work Effectiveness Questionnaire-II (CWEQ-II, Laschinger et al., 2001), and psychological empowerment was measured by the Work Empowerment Questionnaire (Irvine et al., 1999). The organizational culture and climate was measured by the Organizational Social Context measurement system (OSC: Glisson \& James, 2002).

The CWEQ-II (Laschinger et al., 2001) and the Work Empowerment Questionnaire (Irvine et al., 1999) were originally created in Canada, and the OSC (Glisson \& James, 2002) was developed in the USA. Appropriate permissions to use these instruments for the present study were granted by the developers. The instruments were originally produced in English and back-translated from Lithuanian into English (Polit \& Beck, 2015). Both English and Lithuanian language specialists confirmed the validity of the translations. Also the instruments were previously used with nurses in Lithuanian context and were considered to be valid and reliable (Trus et al., 2011; Galdikiene et al., 2016).

The questionnaire was initially piloted in one hospital with three teams of nurse managers $(n=21)$. The Cronbach's alpha values of the piloted questionnaire were considered to be acceptable. The Cronbach's alpha for the CWEQ-II was .71, for the Work Empowerment Questionnaire was .94, and for the OSC was .76. On the basis of the pilot test, some minor linguistic changes were made. The data obtained from the pilot test were not included into the main data of the presented study.

\section{Conditions for Work Effectiveness Questionnaire-II}

The CWEQ-II consisted of 19 items that were divided into six empowering structures: access to opportunity, information, support, resources, and formal and informal power.

The CWEQ-II was measured using a 5-point Likert scale (Laschinger et al. 2001). The scores for each statement indicated the degree of agreement ranging from 1 (none) to 5 (a lot). A subscale score was counted by summing and averaging the items, ranging from 1 to 5 . The overall structural empowerment score was obtained by summing the average scores of each subscale, ranging from 6 to 30. The scores represented a low (6-13), moderate (14-22) or high (23-30) level of empowerment (Laschinger et al. 2011). The Cronbach’s alpha coefficient for the CWEQ-II was .80.

\section{Work Empowerment Questionnaire}

The Work Empowerment Questionnaire included 22 items and spanned three areas of verbal, behavioral and outcome empowerment. 
The Work Empowerment Questionnaire was measured on the scale of 0 to 10, where 0 indicated of no confidence and 10 represented high confidence in the nurse manager's ability to accomplish the task. A subscale score was calculated by summing and averaging the items. The overall psychological empowerment score was calculated by summing the values of all items and then dividing the sum by the number of items. Higher scores represented a stronger confidence in the ability to do the job (Irvine et al. 1999). The Cronbach's alpha coefficient for the Work Empowerment Questionnaire was .92.

\section{Organizational Social Context}

The OSC consisted of three parts: organizational culture, climate and morale. For this study, only the organizational culture and climate parts were used. Organizational culture (42 items) assessed three dimensions, namely proficiency, rigidity and resistance. Organizational climate (46 items) involved three dimensions, namely engagement, functionality and stress (Glisson \& James, 2002).

To assess the dimensions of organizational culture and climate, a 5-point Likert scale was used, ranging from 1 (not at all) to 5 (a very large extent). After performing a factor analysis, it was considered that the theoretical structure of the instrument was slightly supported by the factor solution. The Cronbach's alpha coefficient for the areas of organizational culture and climate ranged from .66 to .88.

\section{Data analysis}

The Statistical Package for Social Sciences (SPSS version 21.0) was used to analyze the data. Descriptive statistics of the data were calculated. Spearman's correlation coefficient was counted to determine the connection between organizational culture and climate and empowerment. Values were considered to be statistically significant at the level of $p<.05$.

In terms of organizational culture and climate, the within-group consistency of responses (index $r_{w g}$ ) was calculated for assessing inter-rater agreement. The index $r_{w g}$ was computed for each of the constructs that composed the culture and climate. It reflects the level of consensus or agreement that exists among the team members when assessing the target item. If all of the team members demonstrate agreement and give the same evaluation for the target, the observed variance is 0 , and the $r_{w g}$ is equal to 1 . Values above the level of .70 indicate a high consistency of responses within the group (Glisson, Green, \& Williams, 2012).

Analyzing the within-group consistency is necessary for composing individual-level responses to higher-level (e.g. team) constructs. In addition, a between-group analysis was conducted using an intra-class correlation coefficient (ICC) and eta-squared to reveal the 
between-group differences among teams on each construct. The ICC (type 1) was calculated via a random intercepts model and shows the proportion of total variance between groups, and the eta-squared value demonstrates the proportion of total variation or sums of squares that exist between groups (Glisson, Green, \& Williams, 2012).

The within-group consistency of responses and between-group differences suggest that appropriate teams were selected for the research. The culture and climate profiles were grouped using hierarchical cluster analysis methods (Ward's clustering method, squared Euclidean distance) (Murtagh \& Legendre, 2014).

\section{Ethical considerations}

This research was performed in accordance with the basic principles declared in the World Medical Association Declaration of Helsinki (2013). Permissions to use the instruments were obtained from the developers. Formal ethical approval was granted by the Ethical Committee of Klaipeda University (Lithuania). Written permissions were also obtained, based on the existing protocols of each hospital.

Before the data collection, the researcher visited each hospital and explained the research-related ethical, methodological and practical issues to the nurse managers during a primary meeting. When collecting the original data, participants were provided with a cover letter presenting the purpose of the study, completion instructions, and the ethical issues involved. Participation was anonymous and voluntary, and participants had a right to withdraw from the research without any explanation. No compensation was offered for participation, and no pressure was exerted from either the researcher or the hospital authorities for participation in this study (Parahoo, 2014).

\section{RESULTS}

\section{Sample}

Nurse managers reported their areas of nursing mainly to be medical (31.6\%) and surgical (32.1\%), although other areas (36.3\%) were mentioned (e.g. mental health, midwifery). Participants had a mean age of 48.4 years (SD 8.9, age range for the teams $40-55$ years). At the time of data collection, the nurse managers had worked in an administrative position for an average of 14.7 years (SD 10.6), and generally in nursing for an average of 27.3 years (SD 9.9).

Most of the nurse managers (43.5\%) had completed their professional education at medical schools (until 2001, when a higher education reform was implemented and medical schools were re-organized into colleges). Approximately a third of the participants had 
received their Bachelor’s degree at universities (26.9\%), some had completed college (16.1\%), and a small number had earned a Master's degree (13.0\%). The majority of the respondents (86.5\%) worked full-time and held a general practice nursing license (94.3\%).

Almost all of the nurse managers (97.4\%) had participated in courses that developed their qualifications during the last 5 years. However, in Lithuania there is a requirement for nurse practitioners to undertake 60 hours of refresher courses over a period of 5 years. In their nurse manager's position, respondents spent an average of $44.5 \%$ (SD 36.0) in direct clinical practice.

\section{Organizational culture and climate}

The analysis offered justification on the aggregation of individual-level responses of organizational culture and climate for measuring team-level organizational culture and climate (see Table 1). The differences in organizational culture and climate between nurse managers' teams and the health care organizations are presented in Table 1. The T-scale scores (mean 50, standard deviation 10) show the variation of differences on the various dimensions of organizational culture and climate (Song et al., 2013).

Comparing the differences in culture dimensions, the differences between nurse managers' teams were significant in the resistance, and significant differences were also found in the resistance and proficiency at the organization level. The most variation seen at team and organization levels was in the resistance dimension of culture. Concerning the climate dimensions, differences between nurse managers' teams were seen as significant in functionality, and significant differences were found at the organization level for engagement and functionality. The most variation seen at team and organization level was in the functionality dimension of climate (see Table 1).

The differences of variation in culture and climate were greater at the organization level than at the team level. Resistance (culture dimension) differed most at the team level, and functionality (climate dimension) differed most at the organization level.

\section{Place Table 1 here}

Several culture and climate profile types can be identified from the data from the teams of nurse managers. Examples of profiles are provided in Figure 1 and Figure 2. As shown in Figure 1a, one of the teams (\#18) was close to the mean scores on the culture dimensions. Team \#11 was relatively high on rigidity and resistance, but low on proficiency, 
whereas team \#2 was the opposite, being higher on proficiency and lower on rigidity and resistance.

Figure $1 \mathrm{~b}$ provides three different cluster representations that were grouped from the culture profiles. It illustrates that one profile seems to be close to a moderate level of culture (Ccu2), whereas others varied between the low, moderate and high levels of the culture dimensions.

\section{Place Figure 1 here}

Figure 2a provides examples of climate profiles. Team \#4 is close to the mean scores on the culture dimensions. Other climate profiles were high or low on one or two climate dimensions. For example, nurse manager team \#18 was lower on stress and functionality. Another team (\#15) scored high on stress related to engagement and functionality.

The climate profiles were grouped into three different clusters. As shown in Figure 2b, one climate profile (Ccl1) had average scores on the climate dimensions. However, other team profiles varied between higher and lower levels on climate dimensions.

Place Figure 2 here

\section{Connections between organizational culture and climate and empowerment}

Several statistically significant correlations were found between culture and climate dimensions, and empowerment and its elements (see Table 2). Nurse managers’ experienced work-related empowerment, and the organizational culture and climate of the teams they worked in were analyzed. Organizational culture and climate seem to be connected with nurse manager work-related empowerment in many areas. However, most of the correlations that were observed were weak (Spearman’s correlation coefficient between - .30 and .30).

In proficient and resistant cultures, nurse managers were both structurally and psychologically empowered. Additionally, when the climate was engaged and functional they also felt empowered. In less stressful climate, nurse managers were more structurally empowered (see Table 2).

When subject to detailed analysis (see Table 2), culture and climate dimensions were clearly connected to empowerment areas. Thus, when working in proficient and resistant cultures, nurse managers had access to opportunity and information, and when the culture was less rigid, they had more access to resources. The verbal and outcome empowerment of nurse managers was also connected to proficient and resistant cultures. 
Concerning organizational climate dimensions: when the climate was engaged and functional, nurse managers had access to opportunity, information, and support, and experienced formal and informal power, also this was connected to verbal and outcome empowerment. Furthermore, when the climate was less stressful, nurse managers had more access to resources (see Table 2).

Place Table 2 here

\section{DISCUSSION}

This study describes the evaluation of nurse managers on their organizational culture and climate dimensions, specifically in relation to work-related empowerment in a Lithuanian context. The results showed that variations in culture and climate were bigger at the team level than at the organization level. In addition, these differences were larger in climate than in culture dimensions. Glisson, Green, and Williams (2012) describe organizational culture as the expectations that guide how work is performed in organizations; while the organizational climate is composed of employees' shared perceptions of the psychological impact of the work environment on their functioning in the organization. Based on our findings, it seems that nurse managers perceive their work environment in the same way when working in teams, but their normative beliefs, behavioral expectations, and organizational values and assumptions are not entirely clear to them. Shared norms and expectations may be determined by the conditions of the work environment (daily work demands), and these may reflect the values and assumptions of the organizational leaders, but not necessarily any other members of the organization. However, the organizational values and assumptions that form shared norms and expectations describe the dimensions of culture, and this serves to explain their impact on the work environment (Aarons et al., 2012).

Our results showed that there were several connections between organizational culture and climate and work-related empowerment, however, most of them were weak, but statistically significant. Nurse managers were both structurally and psychologically empowered when working in a proficient and resistant organizational culture. A proficient culture expects nurse managers to have clinical skills and up-to-date knowledge, and to prioritize the patient's needs and well-being (Glisson, Green, \& Williams, 2012; Glisson et al., 2014; Glisson \& Williams, 2015). According to our findings, nurse managers were quite experienced, with upgraded qualifications, and working not only in an administrative position, but also performing clinical duties in practice. Therefore, it is not surprising that a proficient organizational culture serves to empower them. 
Concerning resistant organizational cultures, nurse managers are expected to suppress any change efforts within their work environment (Glisson, Green, \& Williams, 2012; Glisson \& Williams, 2015). Organizational changes create uncertainty during a change process, and increase feelings of inadequate control relating to roles and tasks. Also, during on-going organizational changes, nurse managers are still required to provide high quality services and uphold their responsibilities (Salmela, Eriksson, \& Fagerstrom, 2013). The organizational leader's task is therefore rather challenging and is directed to minimizing the gaps between perceptions of leaders and staff on organizational changes and encouraging interactive thinking that helps staff understand the process of change.

In regard to organizational climate, nurse managers felt empowered when the climate was engaged and functional. In an engaged organizational climate, nurse managers perceive that they can personally accomplish meaningful activities, be involved in their work, and also remain concerned about the individual patient (Glisson, Green, \& Williams, 2012; Glisson et al., 2014; Glisson \& Williams, 2015). The challenge for nurse managers is to maintain a balance between executing clinical and administrative tasks. However, a nurse manager's engagement can be enhanced by a supportive work environment, and by providing them with autonomy in performing their role (Gray, 2012).

In a functional organizational climate, nurse managers perceive that they have the necessary cooperation and support from co-workers and administrators to perform their work, have an opportunity for personal growth, and have a well-defined understanding of their role for the successful function of the organization (Glisson, Green, \& Williams, 2012; Glisson et al., 2014; Glisson \& Williams, 2015). To prevent inefficiency in their working position, nurse managers need to promote open discussion between staff and administrators. Additionally, to improve functionality, health care organizations should support nurse managers in enhancing their knowledge and skills.

Our findings revealed that when working in a less stressful organizational climate, nurse managers were structurally empowered. A stressful climate can be seen when nurse managers are emotionally exhausted and overwhelmed in their work, and cannot fulfil necessary tasks and responsibilities (Glisson, Green, \& Williams, 2012; Glisson \& Williams, 2015). There is therefore little doubt that lower levels of work stress amongst nurse managers will have a positive impact on individual and organizational outcomes.

\section{Methodological considerations}

Some methodological issues of this present work should be noted. First of all, the instruments used in this study seemed to be both valid and reliable as used in previous nursing studies 
(e.g. Galdikiene et al., 2016; Spencer \& McLaren, 2016; Trus et al., 2011). However, the rigidity dimension of organizational culture (OSC instrument) cannot be considered to be reliable in this research due to a negative ICC. The OSC instrument has previously been used with nurse managers in a Finnish health care context measuring culture and climate, and was found to be valid and reliable (Viinikainen, 2015). However, the OSC instrument was used for assessing team level organizational culture and climate, while the instruments used for evaluating work-related empowerment reflect a more individual level of application.

One limitation that needs to be addressed is that the study sample was formed into teams. Notwithstanding the fact that the established data collection requirements of the OSC instrument were fulfilled, some teams had fewer participants than others. Furthermore, differences in results may occur due to different cultures, practice models and organizational structures when replicating the research using the same instruments and sample. Thus, implementing this kind of research is a challenging undertaking, and a mixed method approach is recommended for understanding the complexities of social contexts.

The data collection was carried out during several months in 2012, that seems to be a limitation. The time frame of data collection is important, but utilizing the data of research may be several years old before it is released and available for use by others.

\section{CONCLUSIONS}

This study provides additional information on the connection between organizational culture and climate dimensions, and work-related empowerment. The work has led us to the conclusion that nurse managers feel structurally and psychologically empowered when working in a supportive environment with a clear mission, tasks and values. Empowerment is more likely to be perceived when there is an appropriate organizational culture and climate in the workplace. Consequently, health care organizations that do not provide a working environment that empowers nurse managers, may meet a significant degree of turnover at this administrative position.

The findings revealed that team level differences of variation on culture and climate were bigger than those seen at an organization level. The assessment of organizational culture and climate may become seen as an important feature for an organization to reach optimal operational performance. Thus, differences in culture and climate offer possibilities to look for new ways of organizing work in hospitals and supporting health care workers.

The study data was collected from nurse managers at a national level, and this provides a basis for identifying differences between countries. However, as there is a lack of research using the OSC instrument with nurse managers, it is possible that the dimensions 
described in this study may yield different results in other types of organizational and cultural settings. It is also felt that future research should investigate organizational outcomes related to working in a particular organizational culture and climate, and monitor the changes that occur over a sustained period of time.

\section{CONTRIBUTION}

Study Design: MT, NG, TS

Data Collection and Analysis: MT, SB

Manuscript Writing: MT, TS, SB, MH, NG, PG

Critical Comments and Intellectual Support: MH, PG

\section{REFERENCES}

Aarons, G. A., Glisson, C., Green, P. D., Hoagwood, K., Kelleher, K. J., Landsverk, J. A., \& The Research Network on Youth Mental Health. (2012). The Organizational Social Context of mental health services and clinician attitudes toward evidence-based practice: a United States national study. Implementation Science, 7, 56. doi: 10.1186/1748-5908-7-56.

Baxter, C., \& Warshawsky, N. (2014). Exploring the acquisition of nurse manager competence. Nurse Leader, 12, 46-59. doi: http://dx.doi.org/10.1016/j.mnl.2013.10.008.

Clark, C. M., Belcheir, M., Strohfus, P., \& Springer, P. J. (2012). Development and description of the Culture/Climate Assessment Scale. Journal of Nursing Education, 51, 75-80. doi: 10.3928/01484834-20111230-01.

Fan, Y., Zheng, Q., Liu, S., \& Li, Q. (2016). Construction of a new model of job engagement, psychological empowerment and perceived work environment among Chinese registered nurses at four large university hospitals: implications for nurse managers seeking to enhance nursing retention and quality of care. Journal of Nursing Management, 24, 646-655. SLẸ:

Galdikiene, N., Asikainen, P., Rostila, I., Green, P., Balciunas, S., \& Suominen, T. (2016). Organizational social context in primary health care. Nordic Journal of Nursing Research, 36, 103-111. doi: 10.1177/2057158516628728.

Glisson, C. (2015). The role of organizational culture and climate in innovation and effectiveness. Human Service Organizations: Management, Leadership \& Governance, 39, 245-250. doi: 10.1080/23303131.2015.1087770. 
Glisson, C., \& James, L. R. (2002). The cross-level effects of culture and climate in human service teams. Journal of Organizational Behavior, 23, 767-794.

Glisson, C., \& Williams, N. J. (2015). Assessing and changing organizational social contexts for effective mental health services. Annual Review of Public Health, 36, 507-523. doi: 10.1146/annurev-publhealth-031914-122435.

Glisson, C., Green, P., \& Williams, N. J. (2012). Assessing the Organizational Social Context (OSC) of child welfare systems: implications for research and practice. Child Abuse \& Neglect, 36, 621-632. doi: 10.1016/j.chiabu.2012.06.002.

Glisson, C., Williams, N. J., Green, P., Hemmelgarn, A., \& Hoagwood, K. (2014). The Organizational Social Context of mental health medical waiver programs with family support services: implications for research and practice. Administration and Policy in Mental Health and Mental Health Services Research, 41, 32-42. doi: 10.1007/s10488013-0517-1.

Gray, L. R. (2012). Nurse manager engagement: a concept analysis. Nursing Forum, 47, 193199. doi: 10.1111/j.1744-6198.2012.00269.x.

Gunawan, J., \& Aungsuroch, Y. (2017). Managerial competence of first-line managers: a concept analysis. International Journal of Nursing Practice, 23. doi: 10.1111/ijn.12502.

Irvine, D., Leatt, P., Evans, M. G., \& Baker, R. G. (1999). Measurement of staff empowerment within health service organizations. Journal of Nursing Measurement, 7, 79-95.

Kanter, R. M. (1993). Men and women of the corporation (2nd ed.). New York, NY: Basic Books.

Laschinger, H. K. S., Finegan, J., Shamian, J., \& Wilk, P. (2001). Impact of structural and psychological empowerment on job strain in nursing work settings: expanding Kanter's model. Journal of Nursing Administration, 31, 260-272.

Laschinger, S. H. K., Wong, C. A, Grau, A. L., Read, E. A., \& Pineau Stam, L. M. (2011). The influence of leadership practices and empowerment on Canadian nurse manager outcomes. Journal of Nursing Management, 20, 877-888. doi: 10.1111/j.13652834.2011.01307.x.

Meng, L., Jin, Y., \& Guo, J. (2016). Mediating and/or moderating roles of psychological empowerment. Applied Nursing Research, 30, 104-110. doi: 10.1016/j.apnr.2015.11.010.

Meng, L., Liu, Y., Liu, H., Hu, Y., Yang, J., \& Liu J. (2015). Relationships among structural empowerment, psychological empowerment, intent to stay and burnout in nursing 
field in mainland China-based on a cross-sectional questionnaire research. International Journal of Nursing Practice, 21, 303-312. doi: 10.1111/ijn.12279.

Miltner, R. S., Jukkala, A., Dawson, M. A., \& Patrician P. A. (2015). Professional development needs of nurse managers. Journal of Continuing Education in Nursing, 46, 252-258. doi: 10.3928/00220124-20150518-01.

Murtagh, F., \& Legendre, P. (2014). Canada Ward's hierarchical agglomerative clustering method: which algorithms implement Ward's criterion? Journal of Classification, 31, 274-295. doi: 10.1007/s00357-014-9161-z.

Parahoo, K. (2014). Nursing research: principles, process and issues (3rd ed.). Basingstoke: Palgrave Macmillan.

Polit, D. F., \& Beck, C. T. (2015). Nursing research: generating and assessing evidence for nursing practice (10th ed.). Philadelphia, PA: Lippincott Williams \& Wilkins.

Pradhan, R. K., Panda, M., \& Jena, L. K. (2017). Transformational leadership and psychological empowerment: the mediating effect of organizational culture in Indian retail industry. Journal of Enterprise Information Management, 30, 82-95. doi: 10.1108/JEIM-01-2016-0026.

Salmela, S., Eriksson, K., \& Fagerstrom, L. (2013). Nurse leaders’ perceptions of an approaching organizational change. Qualitative Health Research, 23, 689-699. doi: 10.1177/1049732313481501.

Schneider, B., \& Barbera, K. M. (2014). The Oxford handbook of organizational climate and culture. New York, NY: Oxford University Press.

Sinha, S., Priyadarshi, P., \& Kumar, P. (2016). Organizational culture, innovative behaviour and work related attitude: role of psychological empowerment. Journal of Workplace Learning, 28, 519-535. doi: 10.1108/JWL-06-2016-0055.

Song, M.-K., Lin, F.-C., Ward, S. E., \& Fine, J. P. (2013). Composite variables: when and how. Nursing Research, 62, 45-49. doi: 10.1097/NNR.0b013e3182741948.

Spencer, C., \& McLaren, S. (2016). Empowerment in nurse leader groups in middle management: a quantitative comparative investigation. Journal of Clinical Nursing, 26, 266-279. doi: 10.1111/jocn.13426.

Trus, M., Suominen, T., Doran, D., \& Razbadauskas, A. (2011). Nurses perceived workrelated empowerment in Lithuanian context. Scandinavian Journal of Caring Sciences, 25, 599-607. doi: 10.1111/j.1471-6712.2011.00871.x.

Van Bogaert, P., Kowalski, C., Weeks, S. M., Van heusden, D., \& Clarke, S. P. (2013). The relationship between nurse practice environment, nurse work characteristics, burnout and job outcome and quality of nursing care: a cross-sectional survey. International 
Journal of Nursing Studies, 50, 1667-1677. doi: 10.1016/j.ijnurstu.2013.05.010.

Viinikainen, S. (2015). Nursing group power and nursing managers' power and organizational social reality (in Finnish). Doctoral Dissertation. University of Tampere: Tampere University Press.

Williams, N. J., \& Glisson, C. (2014). Testing a theory of organizational culture, climate and youth outcomes in child welfare systems: a United States national study. Child Abuse \& Neglect, 38, 757-767. doi: 10.1016/j.chiabu.2013.09.003. 
Table 1. Differences of organizational culture and climate between and within teams and organizations $(n=193)$

\begin{tabular}{|c|c|c|c|c|c|c|c|c|c|}
\hline & \multirow{2}{*}{ Teams $(n=22)$} & \multirow{2}{*}{\multicolumn{2}{|c|}{ Variance }} & \multirow{2}{*}{$\boldsymbol{F}$} & \multirow{2}{*}{ p-value } & \multirow{2}{*}{$\begin{array}{c}\text { Eta- } \\
\text { squared }\end{array}$} & \multirow{2}{*}{ ICC } & \multicolumn{2}{|c|}{ Mean (T-scale)* } \\
\hline & & & & & & & & Min & Max \\
\hline \multirow{6}{*}{ ט) } & \multirow[t]{2}{*}{ Rigidity } & Between teams & 54.7 & \multirow[t]{2}{*}{.52} & \multirow[t]{2}{*}{.95} & \multirow[t]{2}{*}{.05} & \multirow[t]{2}{*}{-.07} & \multirow[t]{2}{*}{42.1} & \multirow[t]{2}{*}{55.1} \\
\hline & & Within teams & 105.0 & & & & & & \\
\hline & \multirow[t]{2}{*}{ Proficiency } & Between teams & 122.2 & \multirow[t]{2}{*}{1.25} & \multirow[t]{2}{*}{.22} & \multirow[t]{2}{*}{.12} & \multirow[t]{2}{*}{.03} & \multirow[t]{2}{*}{43.6} & \multirow[t]{2}{*}{55.7} \\
\hline & & Within teams & 97.6 & & & & & & \\
\hline & \multirow[t]{2}{*}{ Resistance } & Between teams & 204.9 & \multirow[t]{2}{*}{2.32} & \multirow[t]{2}{*}{.00} & \multirow[t]{2}{*}{.20} & \multirow[t]{2}{*}{.15} & \multirow[t]{2}{*}{43.0} & \multirow[t]{2}{*}{61.7} \\
\hline & & Within teams & 88.4 & & & & & & \\
\hline & \multirow[t]{2}{*}{ Stress } & Between teams & 119.6 & \multirow[t]{2}{*}{1.22} & \multirow[t]{2}{*}{.24} & \multirow[t]{2}{*}{.12} & \multirow[t]{2}{*}{.04} & \multirow[t]{2}{*}{43.4} & \multirow[t]{2}{*}{59.5} \\
\hline \multirow{5}{*}{$\begin{array}{l}\text { 氕 } \\
\text { 泾 }\end{array}$} & & Within teams & 97.9 & & & & & & \\
\hline & Engagement & Between teams & 147.7 & 1.57 & .06 & .16 & .07 & 43.5 & 57.7 \\
\hline & & Within teams & 94.1 & & & & & & \\
\hline & Functionality & Between teams & 188.6 & 2.09 & .01 & .19 & .12 & 39.5 & 57.7 \\
\hline & & Within teams & 90.3 & & & & & & \\
\hline
\end{tabular}

\begin{tabular}{|c|c|c|c|c|c|c|c|c|c|}
\hline \multirow{2}{*}{\multicolumn{2}{|c|}{ Organizations $(n=7)$}} & \multirow{2}{*}{\multicolumn{2}{|c|}{ Variance }} & \multirow{2}{*}{$\boldsymbol{F}$} & \multirow{2}{*}{ p-value } & \multirow{2}{*}{$\begin{array}{c}\text { Eta- } \\
\text { squared }\end{array}$} & \multirow{2}{*}{ ICC } & \multicolumn{2}{|c|}{ Mean (T-scale) } \\
\hline & & & & & & & & Min & $\operatorname{Max}$ \\
\hline \multirow{6}{*}{ 氕 } & \multirow[t]{2}{*}{ Rigidity } & Between organizations & 79.7 & \multirow[t]{2}{*}{.79} & \multirow[t]{2}{*}{.60} & \multirow[t]{2}{*}{.03} & \multirow[t]{2}{*}{-.01} & \multirow[t]{2}{*}{42.1} & \multirow[t]{2}{*}{52.6} \\
\hline & & Within organizations & 100.8 & & & & & & \\
\hline & \multirow[t]{2}{*}{ Proficiency } & Between organizations & 274.0 & \multirow[t]{2}{*}{2.93} & \multirow[t]{2}{*}{.01} & \multirow[t]{2}{*}{.10} & \multirow[t]{2}{*}{.12} & \multirow[t]{2}{*}{43.9} & \multirow[t]{2}{*}{54.4} \\
\hline & & Within organizations & 93.4 & & & & & & \\
\hline & \multirow[t]{2}{*}{ Resistance } & Between organizations & 333.8 & \multirow[t]{2}{*}{3.66} & \multirow[t]{2}{*}{.00} & \multirow[t]{2}{*}{.12} & \multirow[t]{2}{*}{.15} & \multirow[t]{2}{*}{45.9} & \multirow[t]{2}{*}{55.7} \\
\hline & & Within organizations & 91.1 & & & & & & \\
\hline \multirow{6}{*}{ 兽 } & \multirow[t]{2}{*}{ Stress } & Between organizations & 155.5 & \multirow[t]{2}{*}{1.59} & \multirow[t]{2}{*}{.14} & \multirow[t]{2}{*}{.06} & \multirow[t]{2}{*}{.04} & \multirow[t]{2}{*}{46.2} & \multirow[t]{2}{*}{53.9} \\
\hline & & Within organizations & 97.9 & & & & & & \\
\hline & Engagement & Between organizations & 321.9 & 3.51 & .00 & .12 & .14 & 43.5 & 54.8 \\
\hline & & Within organizations & 92.5 & & & & & & \\
\hline & Functionality & Between organizations & 359.8 & 3.99 & .00 & .13 & .17 & 42.4 & 55.7 \\
\hline & & Within organizations & 90.2 & & & & & & \\
\hline
\end{tabular}

*Mean (T-scale) presents the variation between teams and organizations. 
Table 2. Spearman's correlations between nurse managers' empowerment at individual level $(n=193)$ and organizational culture and climate at team level $(n=22)$.

\begin{tabular}{|c|c|c|c|c|c|c|c|}
\hline & \multicolumn{3}{|c|}{ Culture } & \multicolumn{3}{|c|}{ Climate } \\
\hline & & Rigidity & Proficiency & Resistance & Stress & Engagement & Functionality \\
\hline \multirow{3}{*}{$\begin{array}{l}\text { Structural } \\
\text { empowerment }\end{array}$} & Correlation & -.122 & $.229^{* *}$ & $.189^{* *}$ & $-.167^{*}$ & $.416^{* *}$ & $.294^{* *}$ \\
\hline & Sig. (2-tailed) & .090 & .001 & .008 & .020 & .000 & .000 \\
\hline & $\mathrm{N}$ & 193 & 193 & 193 & 193 & 193 & 193 \\
\hline \multirow[t]{3}{*}{$\begin{array}{l}\text { Access to } \\
\text { opportunity }\end{array}$} & $\begin{array}{l}\text { Correlation } \\
\text { Coefficient }\end{array}$ & -.110 & $.232^{* *}$ & $.189^{* *}$ & $-.212^{* *}$ & $.375^{* *}$ & $.268^{* *}$ \\
\hline & Sig. (2-tailed) & .129 & .001 & .008 & .003 & .000 & .000 \\
\hline & $\mathrm{N}$ & 193 & 193 & 193 & 193 & 193 & 193 \\
\hline \multirow[t]{3}{*}{$\begin{array}{l}\text { Access to } \\
\text { information }\end{array}$} & $\begin{array}{l}\text { Correlation } \\
\text { Coefficient }\end{array}$ & -.063 & $.178^{*}$ & $.167^{*}$ & -.128 & $.313^{* *}$ & $.282^{* *}$ \\
\hline & Sig. (2-tailed) & .388 & .013 & .021 & .075 & .000 & .000 \\
\hline & $\mathrm{N}$ & 193 & 193 & 193 & 193 & 193 & 193 \\
\hline \multirow[t]{3}{*}{$\begin{array}{l}\text { Access to } \\
\text { support }\end{array}$} & $\begin{array}{l}\text { Correlation } \\
\text { Coefficient }\end{array}$ & -.014 & $.149^{*}$ & .047 & -.078 & $.216^{* *}$ & $.152^{*}$ \\
\hline & Sig. (2-tailed) & .844 & .039 & .513 & .284 & .003 & .035 \\
\hline & $\mathrm{N}$ & 193 & 193 & 193 & 193 & 193 & 193 \\
\hline \multirow[t]{3}{*}{$\begin{array}{l}\text { Access to } \\
\text { resources }\end{array}$} & $\begin{array}{l}\text { Correlation } \\
\text { Coefficient }\end{array}$ & $-.192^{* *}$ & .026 & -.030 & $-.220^{* *}$ & .063 & -.013 \\
\hline & Sig. (2-tailed) & .007 & .720 & .679 & .002 & .380 & .858 \\
\hline & $\mathrm{N}$ & 193 & 193 & 193 & 193 & 193 & 193 \\
\hline \multirow[t]{3}{*}{ Formal power } & $\begin{array}{l}\text { Correlation } \\
\text { Coefficient }\end{array}$ & -.089 & .045 & $.157^{*}$ & -.033 & $.317^{* *}$ & $.149^{*}$ \\
\hline & Sig. (2-tailed) & .218 & .530 & .029 & .653 & .000 & .039 \\
\hline & $\mathrm{N}$ & 193 & 193 & 193 & 193 & 193 & 193 \\
\hline \multirow[t]{3}{*}{ Informal power } & $\begin{array}{l}\text { Correlation } \\
\text { Coefficient }\end{array}$ & -.026 & $.176^{*}$ & .112 & -.089 & $.312^{* *}$ & $.195^{* *}$ \\
\hline & Sig. (2-tailed) & .725 & .014 & .121 & .220 & .000 & .006 \\
\hline & $\mathrm{N}$ & 193 & 193 & 193 & 193 & 193 & 193 \\
\hline \multirow[t]{3}{*}{$\begin{array}{l}\text { Psychological } \\
\text { empowerment }\end{array}$} & $\begin{array}{l}\text { Correlation } \\
\text { Coefficient }\end{array}$ & -.042 & $.148^{*}$ & $.202^{* *}$ & -.004 & $.365^{* *}$ & $.156^{*}$ \\
\hline & Sig. (2-tailed) & .564 & .040 & .005 & .953 & .000 & .030 \\
\hline & $\mathrm{N}$ & 193 & 193 & 193 & 193 & 193 & 193 \\
\hline \multirow[t]{3}{*}{$\begin{array}{l}\text { Verbal } \\
\text { empowerment }\end{array}$} & $\begin{array}{l}\text { Correlation } \\
\text { Coefficient }\end{array}$ & -.065 & $.169^{*}$ & $.161^{*}$ & -.131 & $.285^{* *}$ & $.161^{*}$ \\
\hline & Sig. (2-tailed) & .369 & .018 & .025 & .069 & .000 & .025 \\
\hline & $\mathrm{N}$ & 193 & 193 & 193 & 193 & 193 & 193 \\
\hline \multirow[t]{3}{*}{$\begin{array}{l}\text { Behavioral } \\
\text { empowerment }\end{array}$} & $\begin{array}{l}\text { Correlation } \\
\text { Coefficient }\end{array}$ & -.043 & .081 & $.160^{*}$ & .084 & $.309^{* *}$ & .126 \\
\hline & Sig. (2-tailed) & .553 & .261 & .026 & .245 & .000 & .081 \\
\hline & $\mathrm{N}$ & 193 & 193 & 193 & 193 & 193 & 193 \\
\hline \multirow[t]{3}{*}{$\begin{array}{l}\text { Outcome } \\
\text { empowerment }\end{array}$} & $\begin{array}{l}\text { Correlation } \\
\text { Coefficient }\end{array}$ & .003 & $.225^{* *}$ & $.259^{* *}$ & -.090 & $.400^{* *}$ & $.175^{*}$ \\
\hline & Sig. (2-tailed) & .970 & .002 & .000 & .213 & .000 & .015 \\
\hline & $\mathrm{N}$ & 193 & 193 & 193 & 193 & 193 & 193 \\
\hline
\end{tabular}

* Correlation is significant at the level $p<.05$

${ }^{* *}$ Correlation is significant at the level $p<.01$ 


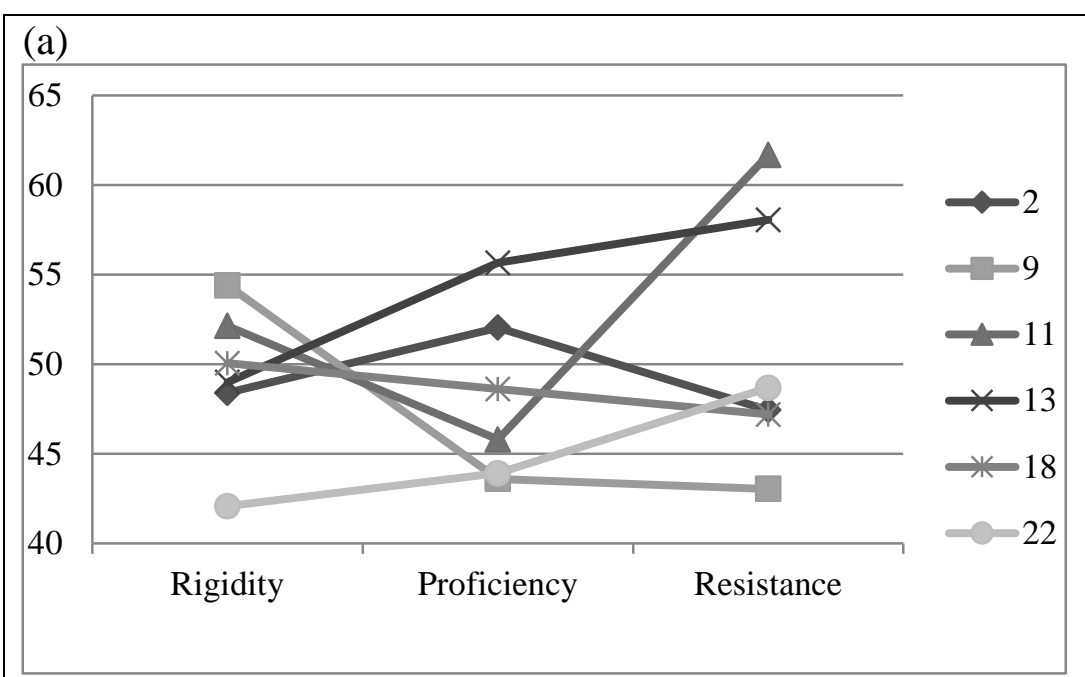

(b)

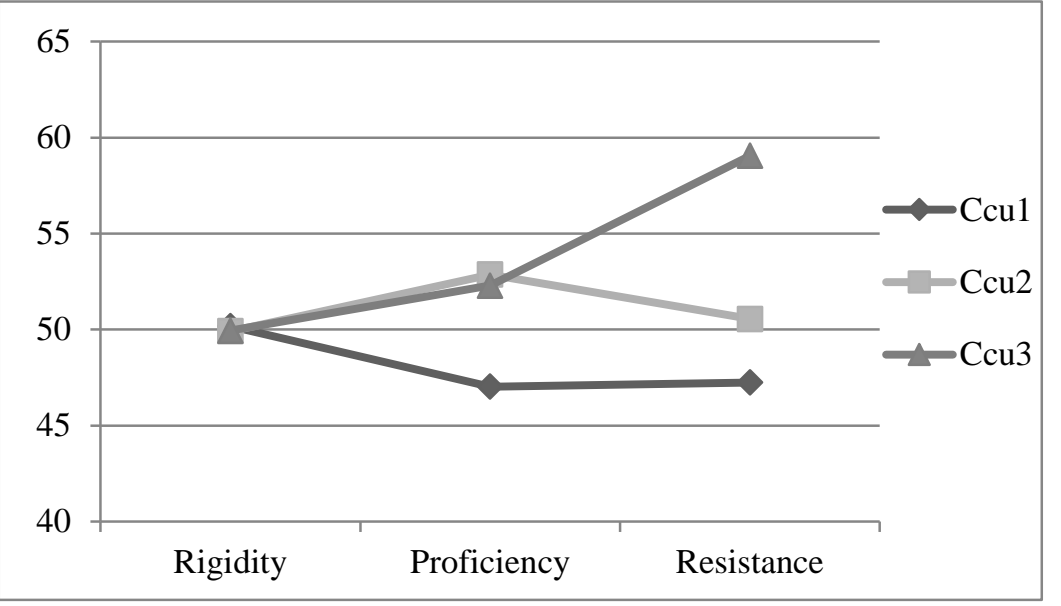

Figure 1. Examples of culture profiles from health care organizations and different clusters between teams $(n=$ 22). (a) examples of culture profiles, (b) culture profiles grouped into three clusters. 


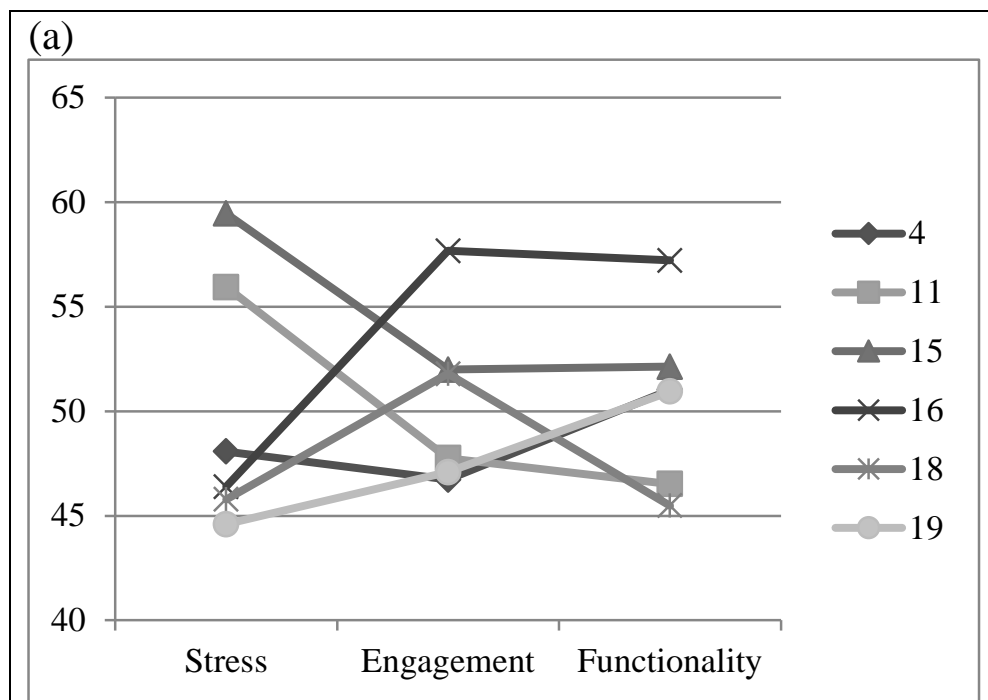

(b)

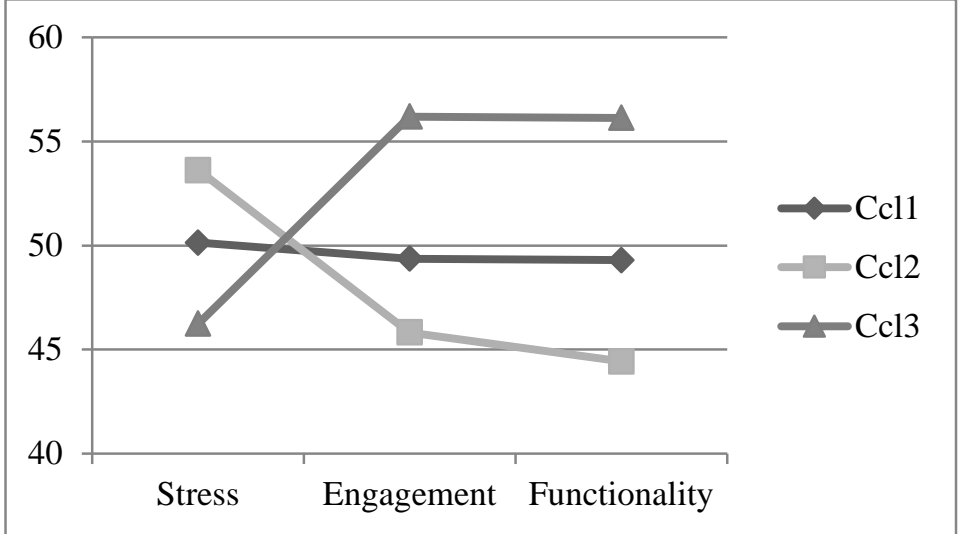

Figure 2. Examples of climate profiles from health care organizations and different clusters between teams $(n=$ 22). (a) examples of climate profiles, (b) climate profiles grouped into three clusters. 